A Fenomenologia como retorno à Ontologia

\title{
A Fenomenologia como retorno à Ontologia em Martin Heidegger
}

\author{
Newton Aquiles von Zuben ${ }^{1}$
}

\begin{abstract}
RESUMO: a elaboração de uma ontologia fenomenológica era uma possibilidade inscrita no próprio projeto filosófico husserliano. Em que sentido, no entanto, o espírito da máxima da "volta às coisas mesmas" serviu de inspiração ao retorno à questão do ser? Em que medida as elaborações ontológicas que se atribuíram o título de fenomenológicas permaneceram fiéis ao espírito geral e às diretrizes formais do pensamento de Husserl? É na tentativa de responder a essas questões que nos propomos examinar a posição especial de Heidegger face ao problema da articulação da ontologia com a fenomenologia. Nossa preferência é ditada pela própria originalidade do emprego da fenomenologia, no autor de Ser e Tempo. O exame do sentido que assume a fenomenologia enquanto ontologia da compreensão, cujo instrumento é a hermenêutica da existência fáctica do homem, exige previamente o delineamento do projeto filosófico fundamental heideggeriano.
\end{abstract}

PALAVRAS-CHAVE: Ontologia. Fenomenologia. Fenomenologia hermenêutica. Dasein.

\section{INTRODUÇÃO}

No epílogo das Meditações Cartesianas, expressava Husserl o desígnio de ver a fenomenologia se constituir como ontologia universal:

A fenomenologia transcendental, sistemática e plenamente desenvolvida, é eo ipso_uma autêntica ontologia universal. Não uma ontologia formal e vazia, mas uma ontologia que inclui todas as possibilidades regionais de existência, segundo todas as correlações que elas implicam. (HUSSERL, 1969, p. 132).

A explícita elaboração de uma ontologia fenomenológica era, portanto, uma possibilidade inscrita no próprio projeto filosófico husserliano. E, de fato, na medida em que as intuições fundamentais de Husserl vieram a desencadear todo um movimento de ideias que se espraiou em diferentes direções e em formas diversificadas de aplicação do método traçado nas Investigações Lógicas, foi, sobretudo no domínio da questão ontológica, que se procurou adotar as diretrizes metodológicas da fenomenologia, numa nova tentativa de leitura do ser. Em que sentido, no entanto, o espírito da máxima da "volta às coisas mesmas"

\footnotetext{
1 Doutor em Filosofia pela Université Catholique de Louvain (1970) Professor Titular (aposentado) da Unicamp, Professor da Faculdade de Filosofia da PUC Campinas.Endereço eletrônico: nzuben@ terra.com.br 
serviu de inspiração ao retorno à questão do ser? E como teriam as ontologias fenomenológicas procurado conciliar as análises regionais do ser com o projeto de uma ontologia geral? Mais ainda, em que medida as elaborações ontológicas que se atribuíram o título de fenomenológicas permaneceram fiéis ao espírito geral e às diretrizes formais do pensamento de Husserl?

É na tentativa de responder quanto possível a essas questões, de modo sucinto, que nos propomos examinar a posição especial de Heidegger face ao problema da articulação da ontologia com a fenomenologia. Nossa preferência é ditada pela própria originalidade do emprego da fenomenologia, no autor de Ser e Tempo. O exame do sentido que assume a fenomenologia enquanto ontologia da compreensão, cujo instrumento é a hermenêutica da existência fáctica do homem, exige previamente o delineamento do projeto filosófico fundamental heideggeriano. Daí dividir-se este estudo em três partes que se impõem naturalmente: a questão do ser; a ontologia fenomenológica; a hermenêutica da existência.

\section{A questão do ser e o projeto da ontologia}

A intenção que preside, como um fio condutor, a todo o desenvolvimento da obra de Heidegger, e lhe confere uma perspectiva unificadora, se expressa na necessidade de reexaminar -repetir - a questão do sentido do ser em geral ou, mais precisamente, a questão da unidade do sentido do ser na multiplicidade de suas acepções. Se tal tarefa se impõe como função primordial da ontologia, é porque a questão do ser foi esquecida. "A questão do ser caiu, hoje, no esquecimento, embora nossa época considere como um progresso aceitar novamente a 'metafísica" (HEIDEGGER, 1960, p.2). Esse tema do esquecimento do ser, que abre Ser e Tempo, já anuncia o binômio velamento-desvelamento como constituindo o ritmo interno do fenômeno ontológico, as duas possibilidades radicais da manifestação do ser. Com efeito, se o sentido do ser veio historicamente a ser esquecido velado - é porque este, de si mesmo, comporta essa possibilidade. De outra parte, a referência à história da metafísica como história da ocultação do sentido do ser já antecipa o tema do tempo como horizonte onde o ser alternadamente se revela ou se dissimula. Como afirma de Waelhens: "Heidegger considera toda ontologia subseqüente como uma monstruosa excrescência sufocando as verdades entrevistas desde o começo. A ontologia foi vulgarizada (Trivialisierung)" (WAELHENS, 1955, p. 4) ${ }^{2}$. Ora, se a questão do ser caiu no esquecimento, é porque o ser se tornou uma noção pretensamente evidente. Os preconceitos que conduziram a essa dissimulação do problema ontológico fundamental, convertendo em doutrina o que na origem era pesquisa e indagação, podem, a

2 As passagens do livro de Waelhens (1955), citadas neste texto, foram todas traduzidas por mim. 
título de exemplo, ser enunciados na forma seguinte, que Heidegger denomina preconceito $(1960$, p. 3):

a) O ser é o conceito mais geral. Heidegger faz referência a Aristóteles (livro B,4 da Metafísica: to on esti katholou málista pánton). É a tese desenvolvida, sobretudo pela filosofia medieval, sobre a universalidade do ser enquanto transcendendo a todos os gêneros e enquanto incluída na apreensão intelectual de qualquer ente. Ora, essa transcendência do ser traz em si mesma um problema da articulação do sentido geral com as acepções particulares que já em Aristóteles permanecia obscuro. Transcendência do ser não é, portanto, equivalente à noção de imediata clareza. O claro aparecer do ser em sua generalidade não é, em verdade, senão a aparência que de fato o dissimula:

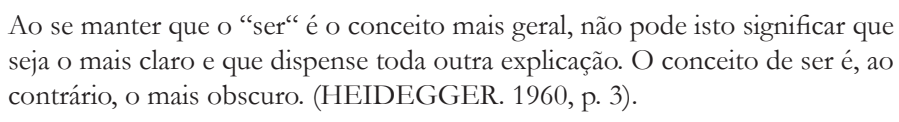

b) O ser é indefinível. É a dedução lógica que se infere de sua absoluta generalidade. Sendo um transcendens, colocado acima de todos os gêneros, o ser não se compadece com uma definição que somente é possível mediante as determinações de gênero e de espécie. Por certo, e esta doutrina envolve um aspecto positivo, ao se assentar sobre a distinção entre ser e ente. Mas pode, igualmente, servir de pretexto para que se descarte o problema ontológico fundamental. Se o ser é indefinível logicamente, não quer isso dizer que não seja indispensável uma interrogação sobre o seu sentido.

c) O ser é um conceito evidente. Não passível de definição, o ser está, no entanto, incluído em todo enunciado a propósito de qualquer ente. E mesmo qualquer comportamento humano, seja em relação ao próprio homem, seja em relação a outro ente, envolve certa compreensão do que seja "ser". Se assim é, por que ainda nos inquirirmos sobre um significado que a todos é patente? Ora, para Heidegger, é exatamente essa compreensão imediata e ordinária do ser, incluída em todo comportamento do homem em relação a si mesmo e em relação aos entes, que suscita a necessidade de uma explicitação:

O fato de vivermos de imediato numa certa compreensão do ser e de, ao mesmo tempo, permanecer o sentido do ser envolvido de obscuridade, demonstra a necessidade fundamental de submeter a questão do ser a uma repetição. (HEIDEGGER. 1960, p. 4).

Alphonse de Waelhens observa que Heidegger “[...] utiliza o termo Selbstverständlichkeit que tem para ele um sentido pejorativo, pois designa não o 
que é evidente, mas aquilo que se faz passar por evidente na ausência de meios de prova" (WAELHENS, 1954, p.5).

Mas não foi somente por se haver tornado uma suspeita noção evidente, que o ser, enquanto questão, foi esquecido. A ausência de uma resposta adequada à indagação sobre o sentido do ser na história da filosofia ocidental se deve ao fato de que a abordagem e o tratamento da questão ontológica se fizeram por caminhos que só poderiam conduzir ao desvirtuamento da própria questão. Com efeito, a interpretação do ser na metafísica ocidental se operou a partir do modelo do ente intramundano, a saber, o ente subsistente. Exemplo significativo desse tipo de interpretação encontramos em Descartes, onde a perspectiva ontológica que o "cogito" poderia abrir é obstruída em seu nascedouro, porque o portador da questão fundamental da filosofia é ele mesmo interpretado como existindo ao modo de ser das coisas, como "res". Se, em Descartes, a questão ontológica não chega a se transformar em interrogação sobre o problema do ser, em geral, é porque o ser é pensado de imediato a partir do modelo de ser da substância, o que faz com que permaneça obscuro o próprio modo de ser da "res cogitans" e, sobretudo o sentido de ser do sum.

Impõe-se, por conseguinte, a escolha de uma nova via de acesso ao tratamento da questão do ser. A ausência de uma resposta certa a essa questão, na ontologia tradicional, e a indeterminação ao dos fundamentos da ciência, que daí resultou, estão a demonstrar que a pesquisa ontológica carece de um fio condutor adequado que lhe permita determinar a condição a priori de possibilidade tanto das ciências que têm como objeto uma circunscrita região do ser, quanto de todas as ontologias que precedem e fundamentam as ciências ônticas. Essa nova via de acesso deverá, pois, possibilitar esclarecer não apenas o sentido do ser dos entes, mas também e necessariamente o sentido do ser em geral:

Toda ontologia, por mais rico e fortemente estruturado que seja o sistema de categorias de que dispõe, permanece cega e trabalha para a falsificação de sua mais autentica intenção, desde que não começa por esclarecer suficientemente o sentido do ser, e renuncia a compreender este esclarecimento como sua tarefa fundamental. (HEIDEGGER. 1960, p. 11).

A resposta à questão do ser somente poderá ser buscada a partir da análise do ente ao qual, por sua própria essência, compete a compreensão do ser. Esse ente entre todos privilegiado é o homem, "pastor do ser", "clareira" onde o ser se manifesta. A abordagem da questão ontológica só é possível, com efeito, a partir da consideração do ente que indaga sobre o ser. "Um só existente tem a possibilidade de interrogar-se. Esse existente é aquele que nós mesmos somos (das wir selbst sind)" (WAELHENS, 1954, p.7). Donde a ontologia fundamental, base 
e perspectiva de qualquer ontologia posterior, dever ser procurada na analítica existencial do homem como Dasein - o ser-aí (Da) do ser, o lugar onde se realiza a compreensão pré-ontológica. Essa analítica já é, portanto, ontológica e não simples consideração ôntica sobre o homem, como encontramos nas ciências. Mais ainda, a própria forma verbal da expressão Dasein está a indicar que o homem não interessa à ontologia por si mesmo. De Waelhens comenta, sublinhando que “[...] o objetivo último e principal é a edificação de uma metafísica geral, que a analítica existencial tem por missão introduzir" (WAELHENS, 1954, p.9).

$\mathrm{O}$ interesse da ontologia se dirige ao ser em geral. Esclarecemos ainda que por analítica existencial entende Heidegger a explicitação das estruturas ontológicas - os "existenciais" - do ser do homem. As estruturas ontológicas próprias aos seres subsistentes (as coisas) serão por ele denominadas "categorias".

A ênfase dada por Heidegger à intenção ontológica das análises da existência humana proíbe qualquer tentativa de interpretação das mesmas, num sentido psicologista ou antropológico. Não é, pois, sem razão que, na "Carta sobre o Humanismo", o autor rejeita expressamente qualquer aproximação entre as orientações fundamentais do seu pensamento com o que se costumou chamar de existencialismo. Quanto a isso de Waelhens observa que Heidegger,

[...] pelo menos em intenção, é um adversário determinado do conceito de filosofia existencial tal como o entende, por exemplo, Karl Jaspers. Este considera a filosofia como sendo exclusivamente uma descrição das possibilidades concretas oferecidas à tal existência humana e isso, sem que o estudo dessas possibilidades possa nos conduzir a uma doutrina geral da existência ou do ser, doutrina contra a qual se insurge a natureza mesma da existência. (WAELHENS, 1954, p.3).

A grandeza do homem não consiste, com efeito, na solidão de sua liberdade, mas na relação ek-stática ao apelo do ser que pelo homem quer se realizar como aletheia - desvelamento. À proposição de Sartre - “[...] precisamente estamos num plano onde há somente homens", Heidegger contrapõe o ponto de vista que domina todo Ser e Tempo: "[...] precisamente estamos num plano onde há principalmente o Ser" (cf. HEIDEGGER, 1964a). Da mesma forma, é com reservas que poderíamos acolher a observação de Jean Wahl sobre uma laicização heideggeriana dos temas de Kierkegaard. Por certo, será sempre possível estabelecer um elo entre os existenciais de Heidegger e as categorias de Kierkegaard. No entanto, será necessário considerar que, enquanto os temas de Kierkegaard exprimem a tensão do homem solitário defrontado ao Absoluto que o transcende, as estruturas existenciais de Ser e Tempo representam as diversas dimensões da abertura do ser-ai à revelação do ser, no horizonte do tempo. 
Enquanto hermenêutica da existência fáctica do homem, a ontologia de Heidegger é decididamente uma filosofia da finitude.

As observações que acabamos de fazer nos reenviam a uma consideração mais atenta da noção de Dasein, ponto de partida e via de acesso ao tratamento da questão ontológica. O termo, na intenção de Heidegger, designa, como vimos, que o homem, enquanto eksistente exposto ao ser, é lugar onde este se manifesta. Se, como se afirma em Ser e Tempo, o homem é um ente em cujo ser há questão de seu ser, o que está aí em questão não é apenas o ser do homem, mas o ser em geral. Em outros termos, na existência humana, o destino do homem e o destino do ser estão em jogo. Essa relação entre o ser próprio do homem, ao qual o "ser-ấ" se associa em seu ser pela compreensão, e o ser em geral, é constitutiva da própria essência do homem. Assim é que, após frisar que o homem tem uma compreensão mais ou menos explícita de seu próprio ser, Heidegger passa imediatamente à afirmação de que a compreensão do ser (ser em geral) constitui uma determinação ontológica do "ser-aî":

O "ser-ấ" é um ente que não é simplesmente dado como um ente entre outros. Ao contrário, ele se caracteriza onticamente pelo fato de que em seu ser há questão deste ser. Pertence, pois à constituição do ser do ser-aí que aja em seu ser uma relação de ser ao seu ser. O que, por sua vez, quer dizer: o ser-aí se compreende sempre de alguma maneira e mais ou menos explicitamente no seu ser. É característico desse ente que com seu ser e pelo seu ser, este ser lhe seja aberto (revelado). A compreensão do seré ela mesma uma determinação_do ser do ser-aí. O caráter ôntico próprio do ser-aí resulta de que o ser-aí é ontológico. (HEIDEGGER, 1960, p. 12).

Vê-se claramente a intenção de Heidegger. Ela se dirige no sentido de superar a ontologia da coisa enquanto modelo de referência da interpretação ontológica do homem. A determinação do ego como "res" somente foi possível na perspectiva de uma metafísica na qual o ser próprio do homem passou a ser esquecido, vindo a ser interpretado ao modo do ser dos entes subsistentes. Donde, também, a relação primordial do homem com os outros entes vir a ser pensada como uma relação entre uma substância espiritual (anima) e outra substância material (mundo) sob a forma de conhecimento. Ora, para Heidegger, além de ser essa relação obscura em seus fundamentos ontológicos, não constitui ela o modo original e primitivo de acesso ao ser. Husserl já havia mostrado que a consciência se identifica à sua abertura ao outro - intencionalidade - enquanto luz que revela os significados do mundo pelo ato mesmo de visá-lo de uma determinada maneira. Em Heidegger, essa noção de intencionalidade reveladora é radicalizada. O ser- ai é luz e revelação, não enquanto consciência, mas enquanto a própria facticidade do seu existir já é radicalmente e inteiramente compreensão 
por ser presença ek-stática ao ser. Não é, pois, primordialmente pelo ver teorético, mas pela relação vivida para com os outros entes e para si mesma que o homem é um ser aberto às várias possibilidades de compreensão do ser.

Vimos, entretanto, que essa revelação do ser, no ser-aí, não é simplesmente um dado, nem mesmo um atributo de algo já constituído. Em outros termos, o ser-ai é um ente cuja essência reside na existência, concebida como um ter-que-ser. O que significa que o ser do homem é essencialmente relação ao seu próprio ser sob a forma de uma radical possibilidade. Essa possibilidade, portanto, constitui o ser do homem como existência. Ora, a possibilidade de ser é sempre mais ou menos explicitamente manifesta ao homem, sob a forma da compreensão que este possui das modalidades possíveis de sua existência pessoal. Compreender (verstehen) o seu ser é para o homem "[...] situar-se a si- mesmo no eixo de suas possibilidades" (BEAUFRET, 1971, p. 25). O projeto de si mesmo no sentido da compreensão de suas possibilidades constitui para Heidegger o conceito formal de existência, enquanto determinação ontológica que distingue o ser-aí pela dos outros entes que não são o ser-aí.

A esta primeira determinação ontológica do ser-aí é necessário acrescentar outra, como contrapolo que a limita. Se o homem é possibilidade de ser, não é, entretanto, possibilidade abstrata e puramente formal. Enquanto sempre-já lançado como ser-ao-mundo ao encontro dos entes intramundanos, o poder ser do homem está sempre ligado a algo, "pre-ocupado". Esse sentimento da situação (Befindlicbkeit), sentimento de estar sempre-já ligado a um determinado mundo que o solicita e o limita, revela ao homem a sua inalienável facticidade.

Em terceiro lugar, o ser-aí como existência projetada sou eu mesmo. O caráter ek-stático do meu ser é o que me possibilita realizar este ser sob a forma de uma escolha radical de mim mesmo:

É porque o homem é essencialmente a sua possibilidade, que ele pode no seu
ser escolher-se a si mesmo, conquistar-se e ou eventualmente não se conquistar
jamais ou não se conquistar senão em aparência. (HEIDEGGER, 1960, p.42).

A possibilidade de autenticidade e de inautenticidade se funda, pois, na existencialidade do ser-aí e na sua facticidade. Resta que, para Heidegger, a inautenticidade, o estado de velamento do ser radical do homem, constitui a modalidade concreta mais geral e de certa forma inevitável do projeto humano. No entanto, essa queda (Verfallen) no inautêntico e no esquecimento do ser radical do homem não é irreversível. Se o ser-aí é essencialmente compreensão de seu ser, a própria inautenticidade supõe a compreensão implícita de uma autenticidade possível. Mas, para essa conversão à lembrança do ser verdadeiro e radical, deve o 
homem passar pela experiência privilegiada da angústia. Nela e por ela, o homem é de imediato arrancado do solo familiar da presença ingênua e tranquilizadora aos seres intramundanos e lançado, em plena solidão de sua ipseidade, no vazio das significações já constituídas, que refluem da superfície do mundo, para dar lugar à brusca revelação da condição original do ser-aí como ser-ao-mundo.

\section{A ontologia como fenomenologia}

O ser é o "transcendens" por excelência, afirma Heidegger, retomando sua obra Vom Wesen des Grundes (HEIDEGGER, 1960, p.38). Portanto, não pode ser demonstrado, porque para isso seria necessário recorrer a algo mais geral que o próprio ser. O ser só pode ser mostrado. Esse processo de "mostração" do ser enquanto fenômeno primordial que se vela e se dissimula no aparecer dos entes coincide com o conceito de fenomenologia como provisoriamente a entende Heidegger, em Ser e Tempo:

A fenomenologia é o modo de acesso ao que deve tornar-se o tema da ontologia; ela é o método que permite determinar o objeto da ontologia, legitimando-o. A ontologia somente é possível como fenomenologia. (HEIDEGGER, 1960, p. 35).

O termo fenomenologia designa, observa de Waelhens,

[...] antes de tudo um princípio metodológico que se expressa na famosa máxima de Husserl " zu den Sachen selbst”; não se reduz a uma palavra de ordem visando a restauração do realismo ingênuo. Ele enuncia simplesmente a vontade de excluir da filosofia os conceitos insuficientemente esclarecidos ou mal fundados, as construções gratuitas ou prévias, os falsos problemas que dizem respeito mais aos preconceitos dos pensadores e as disputas de escolas do que à natureza das coisas. (WAELHENS, 1954, p. 13).

A escolha do método não é, assim, gratuita. Ela se determina pela própria questão fundamental da filosofia, qual seja, a questão do sentido do ser em geral ou, mais precisamente, a indagação sobre a unidade de sentido do ser, na multiplicidade de suas acepções. A antiga aporia aristotélica é retomada sob nova luz. Ora, o que Heidegger visa nesta questão não é à articulação dos entes no Ser entendido como totalidade do existente que será recuperada por uma reflexão total. O que é questionado, na questão do ser, é o fundamento último do ser dos existentes o ser como "transcendens". A "diferença ontológica" - pressuposto radical do ato filosófico heideggeriano - separa de imediato a intenção da ontologia da intenção da "metafísica" (no sentido depreciativo que esse termo recebe, em Ser e Tempo). Se a ontologia não pode adotar o método que propiciou a construção dos grandes sistemas metafísicos, é precisamente porque estes, enquanto sistemas da totalidade 
do existente, só puderam se constituir mediante um pensamento que se erige sobre a base do esquecimento prévio do ser. Impõe-se, por conseguinte, um método que permita "re-descobrir" o que foi ocultado na história da metafísica. Mas, se o ser pode se ocultar, é porque pertence a sua natureza dar-se ao homem sob a dupla forma de velamento e de desvelamento, num horizonte de manifestação que é o tempo. Donde "des-cobrir" o fenômeno do ser é cumprir a tarefa própria da ontologia. O discurso sobre o ser será, pois, um discurso autenticamente ontológico, na medida em que for um discurso fenomenológico.

Dessa maneira, enquanto identificada à ontologia, a fenomenologia será o método que fará trazer à luz o ser como sentido velado nos entes. Para se compreender, no entanto, em todo o seu alcance o sentido de tal identificação, faz-se mister esclarecer melhor o que Heidegger designa precisamente com o termo fenômeno. É, com efeito, a partir da original interpretação dada a esse termo, em Ser e Tempo, que se vai justificar a articulação essencial entre o método e o objeto da ontologia.

A elaboração do conceito formal de fenomenologia é preparada e conduzida pela análise semântica das raízes gregas que entram na composição dessa palavra. Invertendo a ordem seguida por Heidegger, consideremos em primeiro lugar como é operada, em Ser e Tempo, a análise de logos. Razão, julgamento, conceito, definição, constituem sem dúvida elementos determinantes do sentido corrente de logos como discurso. Mas são significados secundários e tardios que encobrem, dissimulando o sentido principal e primitivo. Para os gregos, a função primordial de logos é um apophainesthai - fazer ver aquilo sobre o qual se discorre. De Waelhens comenta: "Quando se refere à sua significação etimológica, fenomenologia quer dizer: leitura, ou ciência dos fenômenos" (WAELHENS, p. 1955, p.14). E prossegue, observando que não se trata de uma leitura interpretativa, mas descritiva. Aliás, o próprio Heidegger enfatiza que a expressão fenomenologia descritiva é "[...] im Grunde tautologish" (HEIDEGGER, 1960, p. 35). Enquanto apophansis, logos é, por conseguinte, o discurso como manifestação daquilo de que se fala. Fenomenologia será, então, o discurso manifestador do fenômeno. Todavia, o que se quer designar por fenômeno, objeto deste discurso?

Phainomenon deve ser reconduzido ao verbo phainesthai - mostrar-se - e à raiz pha ou phos - luz. Fenômeno designa, pois aquilo que em si mesmo se mostra:

Os phainomena os fenômenos são, portanto o conjunto daquilo que está ao claro ou pode ser conduzido à luz, e que os gregos identificavam às vezes simplesmente a ta onta (os entes, o ente). (HEIDEGGER, 1960, p.28). 
Ora, os entes podem se manifestar de diferentes maneiras, correlativamente ao modo por que são abordados. De Waelhens observa com clareza que não seria adequado e correto limitar a extensão do termo manifestar-se à aparência sensível. "Um sentimento, uma obra de arte, uma instituição política, uma cultura, uma doutrina filosófica "se manifestam" de modo tão real quanto uma cor, embora de um modo diferente" (WAELHENS , 1954, p. 14-15). E acrescenta que a inclusão, no âmbito dos estudos fenomenológicos, desses modos possíveis de manifestação é conforme a própria concepção de Husserl, como encontramos nas Ideen.

Em acréscimo, ocorre até mesmo a possibilidade de que venha um ente a se mostrar como aquilo que ele próprio não é. Portanto, neste primeiro momento da análise, já se pode ver que fenômeno tanto pode designar aquilo que em si mesmo se mostra, quanto às maneiras como se mostra, segundo o modo de acesso em direção a ele. Neste último sentido, fenômeno designa a aparência_onde constantemente a verdade dos entes se dissimula ou pode mesmo se ocultar. Devemos notar, entretanto, que o fenômeno enquanto aparência supõe o fenômeno original e nele se fundamenta. Paradoxalmente, é por ser o fenômeno aquilo que em si mesmo se mostra, que pode ele tornar-se uma simples aparência e se ocultar. Daí distinguir Heidegger um sentido vulgar e secundário de fenômeno - o ente enquanto se manifesta desta ou daquela forma - do sentido fenomenológico de fenômeno - o que está velado na manifestação dos entes, o que não é tematizado na experiência ôntica do existente e que, por isso mesmo, necessita ser desvelado pelo operar explicitador da fenomenologia. Nesta acepção, fenômeno é definido formalmente, em Ser e Tempo, como sendo

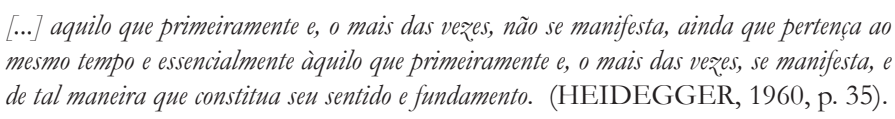

[... $]$ aquilo que primeiramente e, o mais das vezes, não se manifesta, ainda que pertença ao mesmo tempo e essencialmente àquilo que primeiramente e, o mais das vezes, se manifesta, e de tal maneira que constitua seu sentido e fundamento. (HEIDEGGER, 1960, p. 35).

A propósito dessa passagem, de Waelhens observa, em nota de sua tradução de Sein und Zeit (HEIDEGGER,1964, p.284):

[...] esse parágrafo é o momento decisivo no qual a fenomenologia de Heidegger se separa daquela de Husserl, embora seja plausível admitir-se que a necessidade, proclamada insistentemente pro esse último, de se operar uma redução fenomenológica a fim de se esclarecer o que merecerá o nome de "fenômeno"(ou dados) absolutos, resulte em favorecimento em prol da interpretação heideggeriana da idéia de fenomenologia.

A bipolaridade ocultamento-desocultamento, que se radica na própria natureza do fenômeno, irá justificar a necessidade da fenomenologia e, ao mesmo tempo, determinar concretamente a sua tarefa. Com efeito, o fenômeno - no 
sentido de fundamento e significado primordial - não é dado da experiência. Ao contrário, como observa Heidegger, "ser-coberto" é o conceito complementar do conceito de fenômeno. As distinções operadas em Ser e Tempo, a propósito deste "ser-coberto" do fenômeno, não constituem simples exercício formal, mas adquirem extrema relevância no sentido do esclarecimento da questão que desencadeia toda a problemática da ontologia: o esquecimento do ser na história do pensamento ocidental. De que forma pode um fenômeno ser velado? Primeiramente, na medida em que nunca foi ele descoberto._Trata-se do fenômeno que jamais chegou a ser tematizado como objeto de uma pesquisa e de uma tarefa de explicitação. De outra parte, um fenômeno pode ser recoberto. Desvelado outrora, ao menos no sentido de ter sido objeto de uma indagação inicial, o fenômeno veio a recair na dissimulação - no esquecimento da própria questão que o suscitou como problema a ser decifrado. O mais das vezes, essa dissimulação não é total, o que significa que o fenômeno continua a se mostrar, mas simplesmente como aparência. Nesse caso, enquanto interpretado como determinado modo de ser que o sentido primitivo e fundamental do fenômeno corre o risco maior de ser desvirtuado. O que era objeto de uma questão se transforma em doutrina que passa a ocultar para sempre o sentido autêntico da interrogação original, sob a aparência de conceitos que se pretendem evidentes. Não é, pois, sem motivo que Heidegger vê com suspeição o recurso ao critério da evidência em matéria de conceitos filosóficos fundamentais. E, no concernente à questão do ser, foi em virtude de ter-se este tornado um conceito evidente nas doutrinas metafísicas, que o próprio sentido da questão veio a ser esquecido. "O objeto da descrição fenomenológica será, portanto a exposição à vista dos elementos, os menos aparentes dos fenômenos, os quais são também o que os fenômenos têm de mais fundamental: o seu ser" (WAELHENS, 1955 , p. 19).

A necessidade da fenomenologia decorre, por conseguinte, da própria exigência que o fenômeno impõe de ser desvelado. E será ainda a estrutura bipolar do fenômeno - fenômeno original, fenômeno-aparência - que irá determinar a tarefa concreta do método fenomenológico, para Heidegger. A fenomenologia terá a atribuição específica de desocultar o sentido primitivo e fundamental do fenômeno, fazendo-o emergir das aparências imediatas e das interpretações segundas que estão a dissimulá-lo. O método fenomenológico passa a ser, assim, um método regressivo. Por meio de sucessivas aproximações do fenômeno, mediante as quais se opera um processo de decantação e depuração dos significados fornecidos pela experiência, procura-se voltar ao nível dos sentidos primitivos e fundadores que constituem o núcleo positivo de onde se originam as significações derivadas. Donde proceder este método de recuperação dos fundamentos pela formulação prévia das determinações negativas do fenômeno. É o que se faz, por exemplo, a propósito do sentido ontológico do 
fenômeno ser-ao-mundo (in-der-Welt-sein), no $\int 12$ de Ser e Tempo. Heidegger aí observa que é por ter sido esse fenômeno "sempre-já" visto de certa forma, que se impunha a tarefa preliminar da elaboração formal dos caracteres negativos e secundários do mesmo. Contudo, o próprio enunciado dos significados negativos assume um valor altamente positivo, por já revelar a originalidade do fenômeno. Enquanto regressivo, o método fenomenológico é antes de tudo um método de desmascaramento das falsas evidências.

É sabida a preferência que Heidegger concede às análises linguísticas no exercício do método regressivo, fato esse que já se patenteia na própria interpretação do conceito de fenomenologia. Isso se prende à peculiar concepção heideggeriana de que a função do logos é aletheuein = desvelar. Notemos ainda a indicação dada na Carta sobre o humanismo a propósito da linguagem. Esta aí é designada como sendo a "moradia do ser", onde o homem habita como eksistência ex-posta à verdade do ser que é confiada a sua guarda.

Esclarecida a noção de fenômeno e a decorrente maneira peculiar pela qual se elabora o conceito formal de fenomenologia, em Ser e Tempo, restaria ainda justificar por que e a ontologia somente é possivel como fenomenologia. Ora, essa afirmativa de imediato se fundamenta quando se considera, como faz Heidegger, que aquilo que se oculta no aparecer dos entes é justamente o seu ser. Em sua operação de desvelamento, o que deve ser desocultado pela fenomenologia é ser que se dissimula no ente. Em última instância, portanto, o fenômeno em sentido fenomenológico é o fenômeno ontológico:

\begin{abstract}
A fenomenologia é o modo de acesso aquilo que deve tornar-se o tema da ontologia; ela é o método que permite determinar este objeto legitimando-o. A ontologia não é possível senão como fenomenologia. Por aquilo que se manifesta, o conceito fenomenológico de fenômeno visa o ser do ente, seu sentido, suas modificações e suas derivações. (HEIDEGGER, 1960, p.35).
\end{abstract}

\title{
3. A ONTOLOgia COMO FENOMENOLOGIA HERMENÊUTICA
}

As considerações precedentes já possibilitaram evidenciar que a função da fenomenologia, como a entende Heidegger, não é descrever o que se manifesta, mas desvendar o ser que se dissimula no ente. O método fenomenológico se torna um método de explicitação ontológica. Mas, se a fenomenologia é possível como explicitação, é porque existe sempre já no homem uma compreensão implícita do ser, que pode ser trazida à luz por um processo adequado de interpretação. O ser somente pode ser tematizado num saber teorético - numa ontologia porque é compreendido antecipadamente e pré-ontologicamente, no próprio existir concreto e histórico do homem. O que caracteriza essencialmente o existir humano é ser uma ek-sistência, uma abertura à luz do ser. Se a ontologia é possível, é 
porque há uma pré-ontologia que não é "conhecida", mas vivida existencialmente. Sempre já imerso na compreensão do ser pelo seu próprio existir fáctico, o homem somente poderá realizar a obra de tirar o ser do esquecimento, interpretando o que ele próprio já compreende de alguma forma. É por essa razão que, como vimos de início, a via de acesso adequada ao tratamento da questão do ser é, para Heidegger, a analítica existencial do ser-aí (Dasein). A ontologia fundamental será, portanto, uma fenomenologia bermenêutica, no sentido de interpretação e decifragem da compreensão contida na existência fáctica do homem:

O logos da fenomenologia do ser-ai tem a característica de um hermeneuein_que anuncia a compreensão do ser, incluída no ser-aí, o sentido autêntico do ser em geral e as estruturas fundamentais de seu próprio ser. (HEIDEGGER, 1960, p.37).

Todavia, nessa análise interpretativa da existência concreta do homem, não se vai perder exatamente o que se buscava, a saber, a descoberta do sentido do ser em geral? É aqui que a orientação de Heidegger vai se distanciar tanto das intenções das análises existencialistas quanto da intenção de recuperar o ser numa reflexão total, a partir de um eu constituinte último e transcendental, obtido pela redução fenomenológica. Consideremos essa dupla divergência.

Já indicamos a oposição de Heidegger a uma interpretação da existência que se detenha numa ontologia regional do humano, em prejuízo de uma visão ontológica geral. O ser-aí - o Dasein - não designa propriamente a condição humana, mas o modo específico de ser do homem enquanto presença ek-stática à revelação do ser. Ora, o ser que no próprio ser do homem como ek-sistenciia se revela não é somente o ser dos entes subsistentes - o ser das coisas - nem apenas o ser determinado que a ipseidade humana pode assumir, nas diferentes modalidades de seus projetos fundamentais, mas, sobretudo o ser em geral. Antes, existe uma articulação entre essas diversas acepções do ser, operada pela compreensão que o ser-aí realiza de fato. Assim é que o homem corre sempre o risco de interpretar o seu próprio ser, tendo como referência o modelo de ser dos entes intramundanos, como ainda projetar para o sentido do ser em geral essa visão regional da ontologia da coisa. A história da metafísica está a revelar que esta é, de fato, a tendência habitual de compreensão do ser, por parte do homem. É por isso mesmo que a fenomenologia hermenêutica deve ter como tarefa principal corrigir semelhante interpretação, partindo de uma exegese adequada do ser do ente, cuja característica essencial é não existir ao modo dos entes subsistentes. A distinção fundamental em Ser e Tempo entre o ser do ser-aí e o ser dos entes intramundanos não obedece, pois, a uma regionalização dicotômica da ontologia, mas à necessidade de se estabelecer um ponto de partida adequado 
à interpretação do sentido do ser em geral. Ora, esse sentido só pode se anunciar ao homem no horizonte do tempo, que outra coisa não é senão o próprio existir humano como ek-stático, como projeto.

De outra parte, a fenomenologia hermenêutica, ao assumir a função de interpretar, explicitando-a, a compreensão não tematizada, mas já presente de alguma maneira na existência humana enquanto radicada na facticidade da vida e da história, se afasta da intenção husserliana de recuperar o ser na pura visão da consciência transcendental. Para Husserl, a volta às coisas mesmas somente seria possível de efetuar-se mediante a ascese purificadora do distanciamento do mundo fáctico operado pela redução fenomenológica. Heidegger não pode aceitar essa posição, visto que ela the aparece como um retorno por vias transversas ao primado do enfoque gnosiológico e teorético no problema da compreensão do vivido. É por essa razão que, em Ser e Tempo, não se faz recurso à noção de consciência. $\mathrm{O}$ ver fenomenológico não constitui, com efeito, um momento primeiro e fundamental, mas só é possível como possibilidade derivada da compreensão que se exerce originariamente no interior da vida e da facticidade humana. A radicalidade do saber não deve, por conseguinte, ser buscada no nível superior e tardio da redução, mas no nível original da pré-compreensão do ser que constitui a possibilidade radical da existência humana. Se a redução não é necessária, tal se dá porque o homem em seu existir de fato está sempre já ex-posto ao Ser. A hermenêutica da compreensão pré-ontológica será, pois, num sentido privilegiado, a analítica da existencialidade da existência. O ser-no-mundo será a primeira determinação essencial, o primeiro existencial que surge quando o olhar se dirige à existência humana. Convém entender que existencial é, para Heidegger, todo elemento constitutivo do ser da existência humana. E se reserva o termo categoria, para os elementos constitutivos de outros entes que não são segundo o modo de ser do ser-aí (HEIDEGGER, 1960 , p.54).

Ao término destes esclarecimentos sobre a conceituação da fenomenologia em Ser e Tempo, resulta claro que a peculiar maneira pela qual Heidegger a entende, e as articulações que daí decorrem entre os seus diversos momentos significativos, só podem se esclarecer plenamente a partir da questão instauradora do ato filosófico heideggeriano, ao qual a fenomenologia vem se adequar como um método:

\footnotetext{
A ontologia e a fenomenologia não são duas disciplinas diferentes que pertenceriam à filosofia entre outras. Estes dois títulos caracterizam a filosofia segundo o seu objeto e o seu método. A fenomenologia é ontologia fenomenológica universal, que parte da hermenêutica do ser-aí; esta, enquanto analítica da existência, fornece o fio condutor de toda problemática filosófica, fundando-a sobre esta existência, da qual toda problemática surge e sobre a qual todo problema se repercute. (HEIDEGGER, 1960, p. 38).
} 


\section{Conclusão}

Ao converter a fenomenologia em ontologia que deve se fundar numa hermenêutica prévia da existência, Heidegger se inspirava na máxima da volta às coisas mesmas. Recuperar a visão original do mundo equivalia, para o autor de Ser e Tempo, a recuperar o sentido primitivo e velado dos entes, a saber, o sentido do ser. No entanto, a peculiar noção de fenômeno, elaborada mediante a análise linguística, e as implicações metodológicas que daí resultam iriam determinar uma radical divergência em relação às orientações husserlianas básicas. Dessa forma, ao mesmo tempo em que se realizava o voto de Husserl de ver a fenomenologia se constituir numa autêntica ontologia, tal realização se fazia num sentido que vinha contrariar os pressupostos fundamentais os quais deveriam nortear a elaboração da "ontologia transcendental". Não é fácil o esclarecimento completo das razões que levaram Heidegger a trilhar um caminho discordante das orientações do mestre, ao menos na medida em que esse problema é focalizado em Ser e Tempo. Entretanto, das parcas referências explícitas e - o que mais importa - do espírito geral que preside ao desenvolvimento do projeto ontológico heideggeriano, algumas conclusões podem ser inferidas.

Em primeiro lugar, ainda que elaborando de fato um conceito inteiramente pessoal de fenomenologia, Heidegger não deixa de reconhecer o tributo que deve a Husserl, quando reconhece que '[...] as pesquisas seguintes não foram possíveis sem o fundamento estabelecido por E. Husserl, cujas "Investigações Lógicas" abriram o caminho para a fenomenologia (HEIDEGGER, 1960, p. 38).

Em segundo lugar, não obstante a intenção de se inserir numa linha de continuidade às diretrizes do mestre, é de imediato afastada, mediante a categórica interpretação da fenomenologia como sendo um método ao qual se torna indiferente o conteúdo dos objetos de que se ocupa a pesquisa filosófica. A fenomenologia não deve, pois, ser entendida como uma disciplina particular ao lado de outras disciplinas filosóficas, nem mesmo como "um movimento filosófico". Mais precisamente, o próprio método fenomenológico não deve ser encarado como um código de prescrições inalienáveis, mas, antes de tudo, como um foco emanador de inspirações diversas: "Compreender a fenomenologia é compreender as suas possibilidades” (HEIDEGGER, 1960, p. 38).

E, finalmente, ao rejeitar o recurso à noção de consciência e à redução transcendental, e ao substituir a descrição fenomenológica das essências pela ontologia da compreensão, Heidegger se inspira na dupla intenção de superar a primazia do teórico na questão do sentido do ser, e de se afastar do projeto comum a toda a metafísica tradicional, de recuperar o ser enquanto totalidade por uma reflexão que se pretende total. Essas duas intenções de Heidegger se 
aclaram, uma vez que se considera, como já foi indicado, que o ato filosófico heideggeriano é suscitado pela questão do esquecimento do sentido do ser, no pensamento ocidental. Necessário se fazia, portanto, tomar a direção inversa das orientações que permitiram a construção dos grandes sistemas metafísicos. Ora, como foi visto, o que caracteriza a metafísica, enquanto doutrina ou sistema de doutrinas sobre o ser, é, de um lado, a noção de totalidade do existente e, de outro, o esforço de igua1 ar esse ser total à reflexão igua1 mente total. Impunha-se, assim, a Heidegger, por força mesma de seu projeto filosófico, destruir a ilusão metafísica em seus dois polos constituintes. A noção de aletheia preparava toda a crítica posterior de Ser e Tempo à pretensão do privilégio do pensamento reflexivo na compreensão do ser. $\mathrm{O}$ logos, o pensamento discursivo, não é o lugar primitivo da verdade. O logos (no sentido derivado e tardio) não é constituinte da verdade do ser, porque esta não é originalmente construção, mas compreensão. A radicalidade do pensar deve ser buscada na radicalidade do existir. Se um projeto teórico da ontologia é possível, é porque o noein se funda na compreensão pré-ontológica inerente à existência. Existir é o ato filosófico fundamental.

De outro lado, uma reflexão total não é possível, porque o ser não se deixa fechar no ciclo - dialético ou não - do existente. Se for ele o "transcendens" por excelência, já não é lícito à filosofia se erigir em sistema fechado. Embora em plano e em perspectiva diferente, a intuição de Heidegger reencontra a intuição de Kierkegaard. O homem pastoreia o ser, mas este não se deixa enclausurar nos domínios do humano. Se, enquanto hermenêutica da existência finita do homem, a ontologia fundamental é decididamente uma filosofia da finitude, nada nos impede de indagar sobre o que seria uma ontologia geral que permanece ainda no pensamento hedeggeriano como um voto e um projeto. Apontaria ela, talvez, para uma ontologia do "in-finito"? No que a isto concernem os caminhos, a interpretação está aberta, ainda que sejam caminhos que conduzem a parte alguma.

ZUBEN, N. A. von. A Fenomenologia como retorno à Ontologia em Martin Heidegger. Trans/Form/Ação, Marília, v. 34, n.2, p. 71-102, 2011.

ABSTRACT: The development of a phenomenological ontology was a possibility inserted in the Husserlian philosophical project. In which sense, however, the spirit of the maxim of "the return to the same things" was used as an inspiration to the return to the question of the Being? In which extent the ontological elaborations that have incorporated the title of phenomenological remained faithful to the general spirit and to the formal guidelines of Husserl's thought? In an attempt to answer these questions, this brief study aims at examining the special position of Heidegger in face of the problem of the articulation between the ontology ant the phenomenology. Our preference is dictated by the originality itself of the utilization of the phenomenology by author of Being and Time. The 
examination of the sense that phenomenology assumes as ontology of the comprehension, whose instrument is the hermeneutic of the factual existence of the man, requires a previous outlining of Heidegger's philosophical fundamental project.

KEYWORDS: Ontology. Phenomenology. Hermeneutics. Phenomenon. Dasein.

\section{REFERÊNCIAS}

BEAUFRET, Jean. Introduction aux philosophies de l'existence: de Kierkegaard à Heidegger. Paris: Denoel, 1971.

HEIDEGGER, Martin. Sein und Zeit. Tübingen: Max Niemeyer, 1960.

HEIDEGGER, Martin. L'être et le temps. Trad. Rudolf Boehm e Alphonse de Waelhens. Paris: Gallimard, 1964.

HEIDEGGER, Martin. Lettre sur l'Humanisme. Trad. R. Munier. Paris: Aubier, 1964a.

HEIDEGGER, Martin. Kant et le problème de la métaphysique. Trad. A. de Waelhens e W. Biemel. 6 ed. Paris: Gallimard, 1953.

HUSSERL, Edd. Méditations Cartésiennes: Introduction à la Phénoménologie. Trad. G. Peiffer e E. Levinas. Paris: Vrin, 1969.

MAC DOWELL, João A. A. Gênese da ontologia fundamental de Martin Heidegger. São Paulo: Loyola, 1993.

TAMINIAUX, Jacques. Lectures de l'ontologie fondamentale. Essais sur Heidegger. 2. ed. Grenoble: Jérôme Millo, 1995.

WAELHENS de, Alphonse. La Philosophie de Martin Heidegger. 4. ed. Louvain, Belgique: Publications Universitaires de Louvain, 1955.

WAHL, Jean. Études Kierkegaardiennes. Paris. Aubier (sem data).

Recebido em: 8 de maio de 2011

Aprovado em: 15 de julho de 2011

Trans/Form/Ação, Marília, v. 34, n. 2, p. 85-102, 2011 